\title{
Contributions of immigrants to biomedical research in the US: a personal reflection
}

\author{
Sophie Paczesny \\ Department of Microbiology and Immunology, and Pediatrics, Medical University of South Carolina, South Carolina, USA.
}

\section{My story}

I was born in the small town of SaintAvold in northeast France. When I was a teenager, my younger sister developed a brain tumor. Unfortunately, not only was the diagnosis delayed because of the lack of good imaging technology, but the few available treatments were mostly ineffective and had several toxic side effects. While spending a lot of time in the hospital, I witnessed much suffering, and it became clear to me, even at my young age, that robust treatment options were needed and could only be realized through the transformative power of research. I decided then to apply my natural inclination toward mathematics and the biological sciences to developing a career treating patients with malignancies, particularly children. I followed this pursuit of medicine and science and completed my medical degree at the University of Strasbourg and my residency and fellowship in pediatric hematology and oncology in Paris.

In 2000, I emigrated to the United States on a J-1 visa to pursue research in the emerging cancer vaccine field and completed my $\mathrm{PhD}$ in immunology through a collaboration between the Baylor Institute for Immunology Research and University of Paris VII. This fruitful research environment made me almost reconsider my planned return to France to work as a clinic director at the University and Hospitals of Nancy (the equivalent of a tenure-track physician-scientist assistant professor position). I was pleased to again care for patients receiving hematopoietic cell transplantation, the most effective form of immunotherapy before the advent of $\mathrm{T}$ cell therapies. However, I soon missed the academic freedom and outstanding scientific environment that I found in the US and decided to pursue a second postdoctoral fellowship, which was followed by a tenure-track faculty position, at the University of Michigan in collaboration with the Fred Hutchinson Cancer Research Center focusing on the discovery and validation of biomarkers of graft-versus-host disease and graft-versus-leukemia (toxic and beneficial responses to treatment, respectively).

I was then recruited by the Indiana University School of Medicine in 2012, and after eight years, I moved to the Medical University of South Carolina, where I am currently chair of the Department of Microbiology and Immunology and coleader of the Cancer Immunology Program at the Hollings Cancer Center. My research on biomarkers and $\mathrm{T}$ cells (immune cells that guard against infections and cancers) has been translated into clinical trials affecting the treatment of patients receiving hematopoietic cell transplantation for leukemia. This research holds promise for the development of novel immunotherapies and represents my scientific noneconomic contributions. Importantly, my lab has relied on the talent of many foreign-born and US-born trainees, and their teamwork has generated more than 50 positions as well as large grants, bringing increased resources to my respective US institutions.

\section{Immigrants leading biomedical research}

I believe innovative progress depends on the degree of our collective differences. Immigrants bring unique experiences and perspectives that can diversify how we as a community approach problems. In my opinion, several factors contribute to the success of immigrant scientists: (a) recruitment of top students from other countries; for example, in France, only the top $10 \%$ of first-year medical students will become MDs; (b) the opportunity for new

Conflict of interest: The author has declared that no conflict of interest exists

and alternative ideas to blossom in the US science-rich environment, which allows for arguments and failures; (c) the resilience, grit, and opportunism developed by immigrants early in life; and (d) ethnic diversity and particularly group diversity, which were shown to increase impact (using citations as a proxy) by $10.63 \%$ for papers and $47.67 \%$ for scientists (1).

I am only one of many successful immigrants in the biomedical research field (2). The percentage of naturalized citizens in the biomedical workforce has grown from $8 \%$ to $18 \%$ in just the last decade (3). Of the Americans who have won Nobel Prizes in Chemistry, Medicine, and Physics (often regarded as the highest achievement in research), 35\% were immigrants (4). This number may be an underestimate, as it does not include winners who immigrated to America after receiving their prizes, such as Albert Einstein. This trend has accelerated over the years; from 1901 to 1959 , nine immigrants to the US won Nobel Prizes in Medicine compared with 29 immigrants from 1960 to 2019. There are several famous examples: Gerty Cori, born in Czechoslovakia, 1947 winner for her discovery of the course of the catalytic conversion of glycogen; Albert Claude, born in Belgium, 1974 winner for his discovery concerning the structural and functional organization of the cell; and Rita Levi-Montalcini, born in Italy, 1986 winner for her discovery of growth factors. I had the humble honor of coauthoring a paper with Ralph Steinman, a Canadian immigrant who won in 2011 for his discovery of the dendritic cell and its role in adaptive immunity.

Immigrants have contributed to biomedical research in all Western countries. A notable example is Marie Curie, who was born in Poland and an immigrant to France, where she completed her groundbreaking research that led to two Nobel Prizes. At the time, Europe was the epicenter of biomedical discoveries, suggesting 
that this open-border policy for scientists has benefited many Western countries over the years, as long as they have been welcoming and provided the resources and environment for cross-pollination of research ideas.

Our everyday lives have been changed by the COVID-19 pandemic, the biggest global crisis in a century. All our attention was turned toward developing vaccines, including a new type of RNA vaccine. This unprecedented rapid advance was the fruit of years of collaborative research between Hungarian-born Katalin Karikó and Drew Weissman at the University of Pennsylvania (5). This technology was one of the first tested by the cofounders of the German biotech company BioNtech, Turkish-born Ugur Sahin and wife, Özlem Türeci (6, 7). Notably, Stéphane Bancel, chief executive officer of Moderna, an American biotechnology company producing one of the mRNA COVID-19 vaccines, is also an immigrant born in France.

I am honored to be part of the American Society for Clinical Investigation (ASCI). This prestigious organization was founded in 1908 and includes young accomplished physician-scientists, several of whom have become National Academy of Medicine members, National Academy of Sciences members, Lasker Award winners, and Nobel laureates. Balancing dual roles in medicine and research is even more challenging for immigrants (I decided not to follow this path, as mentioned below), but I am pleased to see that an increasing number of immigrants are members of the society and that the incoming president and vice-president are immigrants for the first time in the history of the society.

\section{Challenges hindering diversification}

My experience as an immigrant has not been without challenges. My most difficult challenge has been not being licensed to practice medicine in the US, as my French license is not recognized for equivalence. I chose not to repeat the licensing process because I did not want to lose valuable research time completing something I had already done 20 years earlier. In my opinion, this is a loss for the US, as France, like most European countries, is ranked highly by the World Health Organization for delivering quality and equitable healthcare (8, 9). In hindsight, it would have helped me to learn more about the issue of insurance authorization of treatments, a concept that is not at the forefront of medical care in France, where universal healthcare exists.

Of course, recent changes in the immigration climate have worried me as a researcher who recruits postdocs from around the world. One of my prospective postdocs had to travel to another country's embassy to obtain her visa, while another has not seen his wife in more than a year. These are only personal examples of a bigger problem (2). A note of caution on this point: in response to US immigration restrictions, other countries have attracted more international students and foreign-born scientists, and these immigrants will no doubt continue winning Nobel Prizes whether in the US or other countries. Fortunately, the US immigration policies seem to be easing again.

My greatest concern is about the disparities at large in the US, not only for immigrants, but also for other underrepresented populations. I took a biased approach and mentioned two extraordinary female Nobel Prize winners, Gerty Cori and Rita Levi-Montalcini, but in reality, only 12 of 111 prizes in medicine have been awarded to women (4). In contrast with other trends, the number of female physicians in leadership roles at academic centers has not increased over a 35-year period, instead remaining stagnant at $25 \%$ less than that for males (10), as has women's representation on National Institutes of Health study sections (11).

The most difficult injustice is racial inequality. A recent commentary outlined data about funding disparity, showing the award rate for Black applicants remains 2-fold less that for White investigators. The article also highlighted barriers to success for underrepresented minority (URM) faculty in our profession and proposed an equity policy (12). Awareness and acknowledgement based on facts of racial inequity and disparity are the first steps in finding potential solutions. I have been honored to be chair of two committees on diversity and inclusion at the American Society of Transplantation and Cellular Therapy and, recently, ASCI. These committees include members from diverse backgrounds who are motivated to see changes. We have proposed actionable items ranging from increasing the numbers of women and URM in leadership positions to implementing an abstract category for health equity/diversity at annual meetings and funding travel grants for URM abstract award winners and a URM fellowship grant. These ideas represent only a start.

The famous poem by Robert Frost summarizes my experience as an immigrant biomedical researcher well: "Two roads diverged... and I took the one less traveled by, and that has made all the difference."

Address correspondence to: Sophie Paczesny, Medical University of South Carolina Basic Sciences Building, Ste 203, 173 Ashley Ave, MSC 504, Charleston, South Carolina 29425, USA. Phone: 843.792.1034; Email: paczesns@musc.edu.

1. AlShebli BK, et al. The preeminence of ethnic diversity in scientific collaboration. Nat Commun. 2018;9(1):5163.

2. Aifantis I, Neel BG. U.S. Biomedical research needs more immigrant scientists, not fewer! Cancer Cell. 2020;38(3):308.

3. Heggeness ML, et al. The new face of US science. Nature. 2017;541(7635):21-23.

4. The Nobel Prize Organisation. The Nobel Prize. https://www.nobelprize.org/. Updated February 14, 2021. Accessed February 17, 2021.

5 . Kariko K, et al. Suppression of RNA recognition by Toll-like receptors: the impact of nucleoside modification and the evolutionary origin of RNA. Immunity. 2005;23(2):165-175.

6. Sahin U, et al. COVID-19 vaccine BNT162b1 elicits human antibody and TH1 T cell responses. Nature. 2020;586(7830):594-549.

7. Polack FP, et al. Safety and efficacy of the BNT162b2 mRNA Covid-19 vaccine. $N$ Engl J Med. 2020;383(27):2603-2615.

8. Tandon AM, et al. Measuring Overall Health Sytem Performance For 191 Countries. World Health Organization; 2000.

9. Schutte S, et al. Health systems around the world - a comparison of existing health system rankings. J Glob Health. 2018;8(1):010407.

10. Richter KP, et al. Women physicians and promotion in academic medicine. $N$ Engl J Med. 2020;383(22):2148-2157.

11. Volerman A, et al. Representation of women on National Institutes of Health study sections. JAMA Netw Open. 2021;4(2):e2037346.

12. Stevens KR, et al. Fund Black scientists. Cell. 2021;184(3):561-565. 